\title{
BMJ Global Health The 6-star doctor? Physicians' communication of poor prognosis to patients and their families in Cape Coast, Ghana
}

\author{
Alexandra Caulfield (D , ${ }^{1}$ Amelie Plymoth, ${ }^{2}$ Yvonne Ayerki Nartey, ${ }^{2}$ \\ Helle Mölsted-Alvesson ${ }^{1}$
}

\begin{abstract}
To cite: Caulfield A, Plymoth A, Nartey YA, et al. The 6star doctor? Physicians' communication of poor prognosis to patients and their families in Cape Coast, Ghana. BMJ Global Health 2020;5:e002334. doi:10.1136/ bmjgh-2020-002334
\end{abstract}

Handling editor Stephanie M Topp

- Additional material is published online only. To view please visit the journal online (http://dx.doi.org/10.1136/ bmjgh-2020-002334).

Received 24 January 2020 Revised 3 April 2020 Accepted 4 May 2020

\section{Check for updates}

(c) Author(s) (or their employer(s)) 2020. Re-use permitted under CC BY-NC. No commercial re-use. See rights and permissions. Published by BMJ.

${ }^{1}$ Department of Global Public Health, Karolinska Institute, Stockholm, Stockholm County, Sweden

${ }^{2}$ Department of Medical Epidemiology and Biostatistics, Karolinska Institute, Stockholm, Stockholm County, Sweden

Correspondence to Alexandra Caulfield; a.caulfield1@nhs.net

\section{ABSTRACT}

Introduction Communication is considered a key skill for physicians globally and has formed a central part of medical curricula since the WHO identified it as a key attribute of the ' 5 -star doctor'. Communication of poor prognosis to patients and caregivers is particularly challenging, yet an important example of physicians' clinical communication, and a priority within palliative care research. Knowledge is scarce regarding the different positions physicians adopt during poor prognosis communication, especially in sub-Saharan countries.

Methods This qualitative study took place at the Cape Coast Teaching Hospital in Ghana's Central Region. Physicians in the internal medicine department, with experience in communicating poor prognosis to patients and families on a weekly basis were purposively sampled. Based on the concept of information power, a maximum variation of participants, in terms of age, sex, seniority and experience was achieved after conducting 10 semistructured interviews in March 2019. Positioning theory was used as a theoretical lens to inform study design. The data were analysed through a constructivist thematic analysis approach.

Results Physicians adopted six positions, considered as six different themes, during their communication of poor prognosis: clinical expert, educator, counsellor, communicator, protector and mentor. Physicians' choice of position was fluid, guided by local context and wider health system factors. Physicians' desire to communicate with patients and families in a way that met their needs highlighted three key challenges for communication of poor prognosis: linguistic difficulties, pluralistic health beliefs and the role of family. These challenges presented ethical complexities in relation to autonomy and nonmaleficence.

Conclusion Context is key to physicians' communication of poor prognosis. Communication of poor prognosis is multifaceted, complex and unpredictable. Physicians' communication training should be developed to emphasise contextual circumstances and physician support, and international policy models on physicians' roles developed to include a greater focus on social accountability.

\section{Key questions}

What is already known?

- Globally, communication is considered a key skill for physicians and has formed a central part of medical curricula since the World Health Organization identified it as a key attribute of the ' 5 -star doctor'.

- Communication of poor prognosis is an important yet challenging example of physicians' clinical communication.

- Knowledge is scarce regarding physicians' experiences of communicating poor prognosis, especially in sub-Saharan countries.

What are the new findings?

- Physicians adopt six positions during their communication of poor prognosis: clinical expert, educator, counsellor, communicator, protector and mentor.

- Physicians' choice of position is fluid, guided by local context and wider health system factors.

- Context is key to communication: in this Ghanaian setting, contextual challenges arose in relation to communication across languages, pluralistic health beliefs and ethical complexities relating to the role of family.

- Physicians' desire to communicate with patients and families in a way that addressed these challenges and met patients' and families' needs can be viewed as an aspect of social accountability.

What do the new findings imply?

- Physicians' communication training should emphasize contextual circumstances of communication and provide greater allied support for this area of clinical practice.

- International policy models on physicians' roles, which guide the development of medical school curricula, should place greater focus on social accountability.

\section{INTRODUCTION}

Palliative care is a critical component of the human right to health and is essential to the achievement of universal health coverage, as 
defined by Sustainable Development Goal $3 ;^{12}$ it alleviates suffering and maximises quality of life for patients with life-threatening illness and their families. ${ }^{3}$ Palliative care was recently prioritised on the global health agenda; in 2014, the World Health Assembly voted unanimously to adopt Resolution 67.19 calling on the 'World Health Organization (WHO) and Member States to improve access to palliative care as a core component of health systems'. ${ }^{4}$ Yet globally only $14 \%$ of the 20 million people who require palliative care each year receive it, and $80 \%$ of these live in low-income and middle-income countries (LMIC). ${ }^{5}$ The 2018 Lancet Commission on Pain and Palliative Care cited this area as one of the most neglected dimensions of global health, 'a moral failing and a travesty of justice', and highlighted communication as a key area for development. ${ }^{6}$

Communication is a key component of palliative care, both for the benefits that successful communication conveys on patients, families, staff and health systems, and its significant role in the physician-patient relationship. Specifically, communication of poor prognosis was highlighted as a key area for research by a 2017 conference of palliative care experts. ${ }^{7}$ The benefits of effective communication of poor prognosis are clear. For patients and their families, it is associated with improved therapeutic relationships, understanding, access to care, treatment compliance, quality of life and increased satisfaction with care. ${ }^{89}$ Discussion of prognosis affects concordance between patient and physician about the chance of cure, which in turn influences patients' treatment choices; ${ }^{10} 11$ poor communication leads to higher use of invasive care near death, lower quality of life and worse bereavement outcomes for family and caregivers. ${ }^{9}$ For staff, poor communication contributes to staff burnout, yet is very rewarding when successful. ${ }^{12} 13$ On a societal level, effective communication is associated with more cost-effective use of healthcare. ${ }^{14}$ Despite these clear benefits, communication of poor prognosis is challenging for physicians. ${ }^{15-18}$ In addition, patients' individual information preferences must be considered when communicating prognosis. Though most patients wish to know their prognosis, there will always be individuals who prefer not to know. ${ }^{19-23}$ In addition, existing paradigms which dominate clinical communication training have been criticised for a reductionist approach, which equates skilled communication with atomised communication skills, while underplaying dynamic realities of 'invivo' clinical communication. ${ }^{24}$ Improved understanding of physicians' communication of poor prognosis can help prepare physicians for this task and allow informed critique of these paradigms. ${ }^{24}$

In the early 1990s, the WHO launched the concept of the '5-star doctor', which identified the roles of general physicians as care provider, communicator, community leader, decision-maker and manager. ${ }^{25}$ Since then, the 5-star doctor model has been developed into a 7-star version by a Danish working group and has informed the design of medical curricula globally. ${ }^{26-29}$ There is ongoing debate as to the validity and universality of such roles in this model, yet few studies critique them through situational examples of physicians' everyday clinical practice. ${ }^{26}$ With this in mind, positioning theory informed the design of the study. Originating with the field of social psychology, positioning theory focuses on how individuals' choice of action is affected by local moral context, through explicit attention to the role of rights and actions within an interpersonal encounter. ${ }^{30}$ In this context, it attempts to explain how physicians are influenced by what is happening around them as they communicate poor prognosis, both on a small-scale within that conversation, and on a broader scale from wider health system and cultural factors, thereby allowing the identification of different positions adopted by physicians during their communication of poor prognosis. For example, a physician could position herself as a 'clinical expert' in a situation where it was clear that the patient was looking for clinical expertise, or a 'counsellor' if they were seeking to discuss concerns. Positioning theory has not previously been applied to communication of poor prognosis, and only very recently to another example of physicians' clinical communication. ${ }^{31}$ This novel application therefore provides a new theoretical insight into this area of clinical communication. Though more dynamic, positions can be considered similar to the roles identified in the 5-star and 7-star doctor models, and can therefore be used to critique these models using an example of daily clinical practice. This is of value for examining how communication of poor prognosis fits within the broader picture of international debate regarding the roles of physicians.

Research on communication of poor prognosis is currently centred on high-income settings with clear structures for delivery of palliative care. ${ }^{32}$ In an African context, recent studies from Tanzania and South Africa have highlighted such communication as a challenging area of clinical practice, and called for the development of culturally relevant communication training in medical schools. ${ }^{1516}$ No studies have been published on this topic in Ghana. However, a recent training review cited 'care of the terminally ill' as a key area for development, and poor communication has been implicated in complaints from patients' families. ${ }^{33} 34$ The aim of the study was therefore to understand how physicians position themselves during communication of poor prognosis to patients and families in a hospital setting in Ghana.

\section{METHODS \\ Setting}

This study took place within the internal medicine department of Cape Coast Teaching Hospital (CCTH) in Ghana. This is the largest hospital in Ghana's Central Region providing care to over 10000 inpatients and 100000 outpatients each year. Physicians in CCTH work as salaried public sector workers. The team in the internal medicine department comprises a consultant, a resident and a house officer. There is no formal palliative 
34 eligible physicians identified

from departmental rota

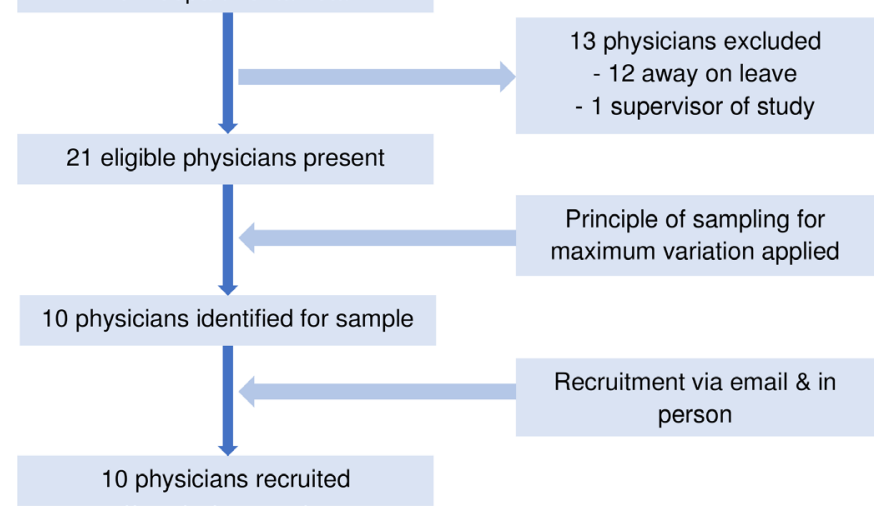

Figure 1 Sampling and recruitment strategy.

care service within the hospital but the internal medicine department provides palliative care to a wide range of patients, including patients with cancer and HIV.

Ghana, like many LMICs, now faces a 'double burden of disease'; non-communicable diseases and injuries are increasing; ischaemic heart disease and cancer are now among the top five causes of death after malaria, pneumonia and neonatal disorders. ${ }^{35}$ Life expectancy at birth is 62 years for males and 64 for females. ${ }^{36}$ The population is increasing and ageing, and undergoing rapid urban migration following socioeconomic development to LMIC status. ${ }^{36-38}$ The National Health Insurance Scheme faces significant logistical problems and declining membership, thus many patients pay out-ofpocket for healthcare. ${ }^{39}$ Nationally, the adult literacy rate is $79 \%$, and almost all Ghanaians self-identify as religious (71\% Christian, 18\% Muslim and 5\% Traditionalist). ${ }^{41}$ Around $70 \%$ of the population depend exclusively on traditional medicine for their healthcare. ${ }^{42}$ Legislation and policies starting in 1991 have attempted to provide organisation and cohesion to practitioners of traditional and alternative medicine (TAM), an umbrella term which includes herbalists, religious/faith healers and traditional medicine-men, following a study from Accra by Kpobi and Swartz. ${ }^{44}$ Such categorisations are problematic, and it is noted that for example, Christian faith healers are often not included within this categorization as their activity is seen as primarily religious rather than medical. ${ }^{44}$

Against this background, palliative care has recently been prioritised on a national level; the Ghana College of Physicians and Surgeons has recently designated palliative care as an approved subspecialty of Family Medicine and Ghana is now ranked third among African countries in this area. ${ }^{456}$ Nevertheless, provision remains 'isolated' (WHO), with only $0.3 \%$ of those who need palliative care able to receive it. ${ }^{57}$

\section{Study design}

This study was based on qualitative, semistructured interviews with physicians, ranging from 43 to $80 \mathrm{~min}$. Throughout, the study design was grounded in a constructivist epistemology using positioning theory to inform study design. ${ }^{48}$ The COnsolidated criteria for REporting Qualitative research tool directed the reporting. ${ }^{49}$ Interviews were conducted in English by a female British physician (AC), in CCTH doctors' offices during March 2019. Participants were invited to use the local language Twi if they wished. Translations were provided by participants themselves and any necessary clarifications sought from an author fluent in Twi (YAN). Transcripts were then checked against original recordings to ensure accuracy and participants contacted for a short member check to clarify any inaudible sections of recordings. ${ }^{50}$ The research team members had extensive research and clinical experience within internal medicine in Ghana, and in applied qualitative methods in resource-scarce settings.

\section{Participant selection}

Sampling and recruitment were conducted in three stages from February to March 2019 (figure 1). First, the rota for the internal medicine department was used as a sampling frame to identify potential participants meeting the inclusion criteria, namely that they communicated poor prognosis at least once on a weekly basis. Those who were absent during the study period were excluded. Second, participants were sampled purposively from this list, maximising sample variation for age, gender, seniority and experience. Third, participants were contacted via email to establish initial interest, then again in person to set up the interview. Sampling was undertaken by the CCTH supervisor (YN) for logistical reasons. Ten physicians were recruited into the study (see table 1) using the concept of 'information power' to guide sample size. ${ }^{51}$ Written consent was obtained from participants prior to interview (see online supplementary appendix 1).

\section{Interview guide}

To meet the aim of this study, an interview guide (see online supplementary appendix 2) informed by positioning theory was developed following a literature review. The guide was validated by an expert in palliative care research from the UK and an internal medicine physician from Ghana. It was then pilot tested in Sweden and Ghana prior to use. Key questions were highlighted prior to data collection to ensure that the same questions were prioritised if time was limited. In addition, participants

\begin{tabular}{ll}
\hline Table 1 Characteristics of study participants \\
\hline Characteristic & Range within the study \\
\hline Age & $26-49$ years \\
Gender & 5 male, 5 female \\
\hline Medical school* & Accra, Cape Coast, Kumasi \\
Position* $^{*}$ & $\begin{array}{l}\text { House officer, resident, } \\
\text { specialist, consultant }\end{array}$ \\
Time as a physician* $^{*}$ & 5 months-24 years \\
\hline
\end{tabular}

*Provided as ranges across the sample, to ensure anonymity. 
completed a short demographic questionnaire prior to the interview (see online supplementary appendix 3 ).

\section{Data analysis}

Thematic analysis, as described by Braun and Clarke, ${ }^{52}$ was chosen as the method of analysis based on its flexibility of application. ${ }^{53}$ Transcripts were imported to the qualitative software Nvivo V.12 (QSR International) and read for immersion in the data by AC. Transcripts were then coded systematically, first with open coding then using codes refined with reference to positioning theory. Codes were then sorted into different themes to broaden the level of analysis. Themes were initially identified and refined through ongoing discussion with the research team. This process was undertaken in two steps; first all collated extracts for each theme were examined for coherence to that theme. Second, themes were examined for 'accurate representation' of the data set as a whole, comparing across individual interviews. Finally, themes were defined and named through discussion with the research team.

\section{Patient and public involvement}

The research was designed and conducted without patient or public involvement.

\section{RESULTS}

Six main positions were adopted by physicians during their communication of poor prognosis. These form the themes of analysis, with subthemes discussed under each (figure 2). Key quotations are provided to allow access to participants' voices. Quotations were selected for their

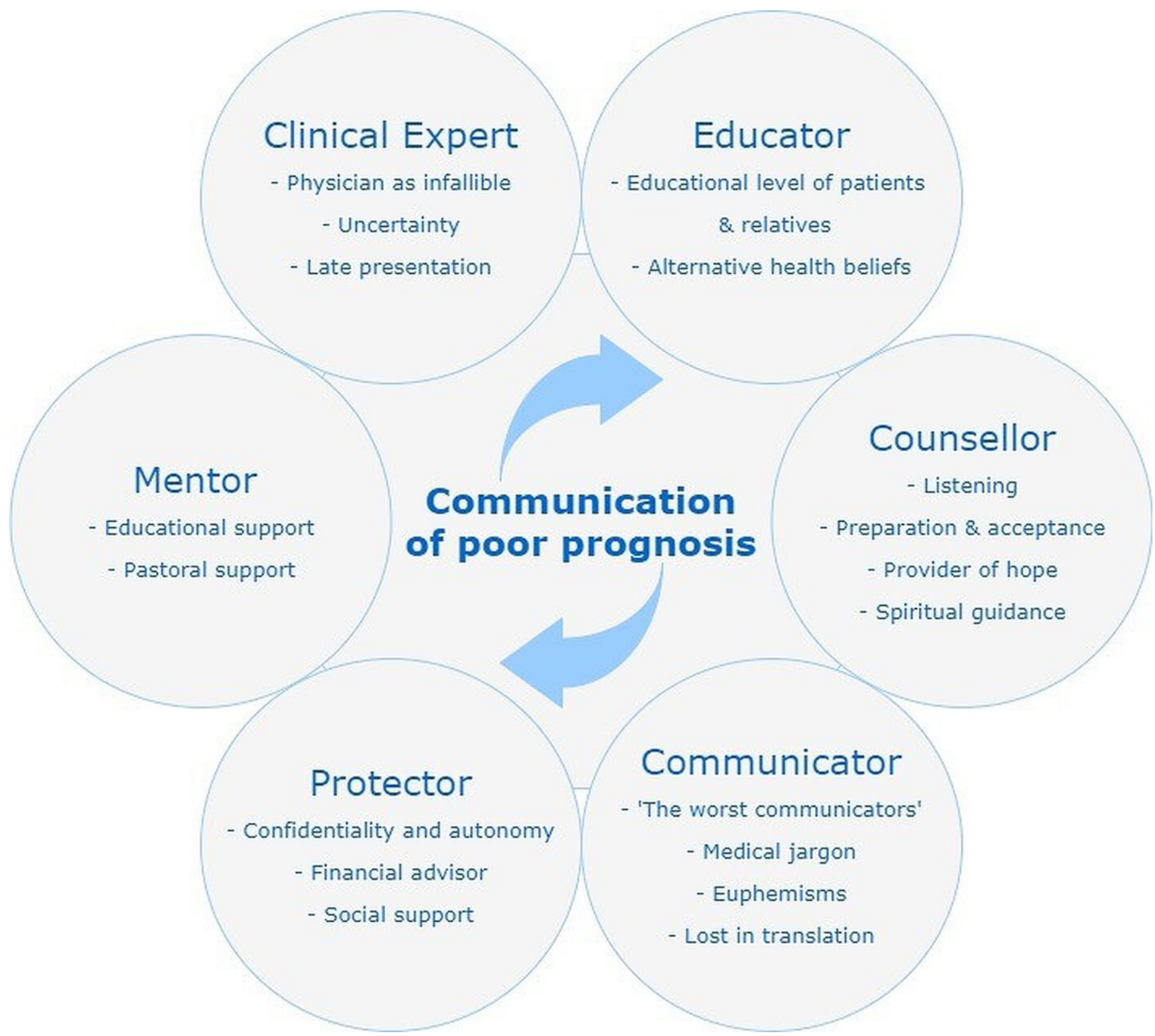

Figure 2 Positions adopted by physicians during communication of poor prognosis with subthemes listed under each. 
illustration of key points, and for diversity across participants' level of seniority.

\section{Physician as a clinical expert}

Physicians identified their default position as a clinical expert able to investigate, understand and treat patients' medical conditions. As clinical experts, physicians sought advice from colleagues in different specialties, both within and outside Ghana. Therefore, this position also comprised a gatekeeping aspect. Physicians perceived most patients to hold a strong and unquestioning acceptance of their position as clinical experts. As a result, they were often given control over clinical decision-making without dialogue.

they don't want to even be involved in the decision... if you ask them... if you give them the option they will say doctor please choose for me... they don't want to go into any discussion with you... they will ask you to make the choice for them... and therefore your discussion of death is very critical... (Consultant/Specialist)

Physicians expressed discomfort at this perception, noting its impact on patient autonomy and the significant decision-making burden it placed on them, and instead welcoming patient input into care. The occasional age difference between young doctors and older patients was noted as going against the cultural norms. In addition, this perception complicated physicians' decision to raise the topic of death and dying; mentioning death could be seen as calling on it. By contrast, the position of clinical expert was challenged by prognostic uncertainty and patients' late presentation to the hospital, often perceived to be a result of financial limitations and strong beliefs in TAM.

\section{Physician as an educator}

The position of educator was linked to the degree of information patients and relatives sought and already knew about their prognosis, as well as their educational background and health beliefs. Education was seen as an ongoing process, in particular as emotion in relation to poor prognosis may impair an individual's ability to absorb new information. Physicians noted that patients came from varied educational backgrounds. Limited health literacy was seen as a cause of potential mistrust of physicians who raised the topic of death and dying. Additionally, many patients held strong beliefs related to TAM.

for instance the person may say that alright that disease that is disturbing my mummy or my father is actually a witchcraft spirit and so we'll have to exorcise that witchcraft... and that is all that they know about... so if you let this person out of the consult and they go back home they are never coming back... they are going to be roaming the spiritual churches when you know that it's a case of cancer... (Consultant/Specialist)

Physicians therefore saw themselves as providing education to patients who may diagnose and treat illness within entirely different models of causation. TAM remedies were seen as detrimental if they caused clinical harm to the patient or delayed their presentation to the hospital. However, physicians also acknowledged their value as a source of hope to individuals in a very vulnerable position.

if they are going to seek for altern-... spiritual help so far as they are not drinking anything that is going to be harmful for them that is their belief... sometimes... sometimes at a point all that people have is their belief and you don't have to take that away from them... (Consultant/Specialist)

In this respect, physicians adapted to individual patient beliefs. Education was important but should not be prioritised at the cost of destroying hope for illnesses which were incurable. This was therefore an example of situational positioning, where the position of educator overlapped with that of counsellor.

\section{Physician as a counsellor}

Physicians described adopting the position of counsellor to patients and relatives, listening to those who needed to talk, and offering hope as an antidote to potential distress caused by a poor prognosis. Their aim was to facilitate a feeling of acceptance, thereby easing the grieving process and allowing preparations to be made for the future. The position of counsellor was multifaceted, with different elements unified by an association with more innate qualities rather than clinical training or expertise. Silence and physical presence were key attributes:

I held his hands quietly... silence itself is a lot of mercy... (Consultant/Specialist)

They offered emotional strength to patients and relatives, often prioritising this over displaying their own emotions. Sometimes this proved impossible, for example when they had formed a strong bond with the patient and felt a deep sense of loss; at these times, physicians often found themselves comforted by patients or relatives, so the carer became the one cared for.

the woman was dying... like I could see that she was going... the husband was standing there... I took hold of the husband outside... and spoke to him and he cried... and he cried on my shoulders... that's like a 76-year-old man crying on a... 33-year-old girl's shoulder... it was tough... I actually shed a tear that day (Consultant/Specialist)

Exploration of a patient's spiritual beliefs was mentioned as a holistic part of care, but not all physicians felt comfortable offering spiritual guidance, viewing it instead as the remit of religious figures.

\section{Physician as a communicator}

Physicians emphasised their position as communicators of clinical information to patients, relatives and colleagues. This position was strongly interlinked with other positions; there was a sense that physicians could not successfully adopt any other position without effective communication skills. 
you can be the best doctor out there but if you don't know how to communicate what you know to the people that you are doing it for then... excuse me but (then) you are useless (Consultant/Specialist)

Despite this, physicians identified themselves as poor communicators, noting difficulties avoiding medical jargon and communicating across different local languages. Illustration and translation via nursing colleagues were employed as methods to communicate from English to local languages, but physicians described a sense of failed communication, and difficulties expressing empathy. In particular, communication was key to negotiation of the topic of death and dying, with which physicians described a complex relationship; torn between an obligation to raise the topic, driven by the moral imperative of honesty and allowing patients to prepare, and a desire to avoid the topic, based on personal discomfort, desire not to cause distress and societal taboo surrounding death. Physicians employed euphemisms to demonstrate cultural sensitivity.

our culture wouldn't really accept you going straight for telling people look you have a year to two years at most... we are not... Ghanaians don't really take... it's going to be like we are basically telling you "you are going to die"... in effect I am telling you that-but I'm giving you time to plan... but we don't see it as giving you time to plan... it will be seen as... we are writing them off... we are writing them off... so... well the trick I picked up... we usually leave it as 'anything can happen' (House Officer)

\section{Physician as a protector}

Physicians often found themselves acting as a protector for their patients, particularly for vulnerable patients who had lost decision-making capacity due to illness or poverty. They did not seek out this position, but felt necessary to adopt it due to perceived threats to patients' well-being, relating to finances, stigma and ethical concerns around autonomy and confidentiality. Physicians offered financial advice, explained treatment costs and made personal contributions towards patients' care if it was not covered by the National Health Insurance Scheme. In addition, they sought to understand patients' social networks. This was particularly important in conditions which carried stigma, such as HIV, and in considering potential causes of division within families. For example, funerals could be a source of financial strain and division in families.

funerals are big things in Ghana... and people can go into debt because of that... there can be division in families because of that... you see that all those things are done properly... that everybody understands their role...

(Resident)

Third, it was often difficult to identify which relative was the primary decision-maker for patients who had lost capacity, with relatives occasionally claiming this position only after financial resources were no longer required. that's an issue currently we have in our setting because erm... when the patient is admitted to the ward... we try to find out who exactly is relative... who exactly is not a relative... yes... and even among the relatives... you want to know... should I say... who exactly has erm... who's been given the mandate to make decisions... on behalf of the patient... normally in our society we don't have written documentation... so sometimes people claim... I'm the uncle... I'm the wife... I'm in charge... it's always been an issue... (House Officer)

Additionally, the concept of patient autonomy was challenging; in many cases, relatives made decisions for patients, either by patient choice or as funders of care. This created an ethical challenge in cases where patient's and relatives' wishes were at odds. For example, physicians described relatives withdrawing funding for care once they learnt that treatment was no longer curative, often to save money for a funeral.

sometimes it's not always easy because... most of the time when they get to know that... this prognosis is bad... or... there's nothing that can be done for this patient other than what he's already receiving... or she's already receiving... sometimes they do not take it well... they either withdraw... in terms of their support... or... they make decisions maybe contrary to what we would want them to do... for example we diagnosed a patient of hepatocellular carcinoma... then when they get to know that nothing can be done for the patient... so maybe continuing with medication... they say... ok doctor you said nothing can be done... so let our patient... let our ward go home... we will try herbal preparations or work... which would be against our directive... or... the patient would want to continue with the medical treatment but the relatives would say... no we can't afford actual-... it's not going anywhere... we are not going to waste our money... (House Officer)

\section{Physician as a mentor}

Physicians described being mentors to more junior colleagues. If workload permitted, communication of poor prognosis was conducted as a team, comprising house officer, resident and consultant and with a nurse or chaplain occasionally present. Junior and senior physicians described reciprocal learning from these shared experiences.

it's best you talk to your colleagues... your senior colleagues... who maybe tell you ok in this our setting we do it this way... this way... you can contact this person... you can contact this person... you can call in this personnel to come in... that's how you can find help... (House Officer)

In contrast to other positions, this position was defined by its adoption towards colleagues and comprised a pastoral element, comprising a strong support network with colleagues, tempered by a sense of hierarchy based on age and experience.

I feel very emotional... I feel for the patient... I feel like if I were the patient I would be... I would feel very bad... 
so I usually go with a senior colleague or... one of my colleagues to help me... just to keep a brave face... (House Officer)

Overall, physicians valued the position of mentor and discussed the potential for development of reflective sessions in which they could share experiences on communication of poor prognosis. The interview process was cited as a positive example of reflection.

It's nice! I don't think anybody ever asks you these questions [laughs]... we usually fill in questionnaires you know... (Resident)

\section{DISCUSSION}

\section{Communication in context}

This study sought to understand how physicians communicate poor prognosis to patients and families within a Ghanaian hospital setting. The importance of context and social accountability were highlighted in the results, with social accountability here exemplified as communication informed by the needs of the community the physicians serve. Physicians' desire to communicate with patients and families in a way that met their needs highlighted three key challenges for communication of poor prognosis: linguistic difficulties, pluralistic health beliefs and the role of family. Specifically, these challenged physicians' position as clinical expert, educator and communicator, and emphasised their position as protector. First, the finding that communicating poor prognosis across languages is challenging echoes recent studies from South Africa and Tanzania, ${ }^{15} 16$ and suggests that communication training which incorporates language training may also be relevant in this context. However, we acknowledge the very real logistical challenges related to this in such a multilingual country as Ghana. Second, discussion of population health beliefs and specifically the role of TAM in Ghana is very topical; increased integration of traditional medicine has been viewed as an aspect of social accountability, which creates health workers with skills relevant for the communities they serve. ${ }^{54}$ Our study suggests that an understanding of TAM is important for effective communication of poor prognosis, and that local belief models must be negotiated within the provider-patient relationship. Third, families played a prominent role in communication of poor prognosis; indeed, physicians often assumed by default that 'communication of poor prognosis' referred to discussion with families rather than patients. This supports the findings of a recent study from Tanzania, which found that family were key to communication of poor prognosis, and that physicians' communication of poor prognosis was underpinned by the African philosophy of Ubuntu, an ethos of solidarity and interdependence with others. ${ }^{16}$ In addition, families were often decision-makers for patients' care, a finding relevant to current debate on the universality of ethical models which prioritise patient autonomy. It has been argued that the concept of 'relational autonomy', in which decision-making is shared between patient and family, is more relevant to non-Western settings. ${ }^{55}$ The concept of 'relational autonomy' was valid in this setting, and presented ethical challenges for physicians in cases where family and patient disagreed. Future studies could consider in more detail the philosophy of Ubuntu and concept of 'relational autonomy' within communication of poor prognosis in other sub-Saharan contexts, and could characterise the dependency between different positions identified in this study, with the aim of incorporating them into practical communication training.

\section{Protecting patients and providers}

The position of protector is a novel finding in relation to previous research on medical roles. Its prominence in this study is likely to be related to wider health systems factors. In this setting, patients were particularly vulnerable to threats against their autonomy, catastrophic health expenditure and alternative belief models which delayed presentation to hospital. However, it is well documented that physicians in many settings worry about causing emotional harm in communicating poor prognosis. ${ }^{151656}$ This is not related to setting but a more inherent ethical problem in being the bearer of bad news. Likewise, all health systems have individuals who struggle to meet costs of care, including indirect costs related to transport and lost income. Therefore, the position of protector has universal elements but is emphasised by particular attributes of health systems.

Turning the lens towards the physicians themselves, the position of mentor is a relatively new finding and worth considering in light of the growing body of research on health worker protection and its contribution to wider health systems. ${ }^{57}$ The position of mentor was recently identified in a South African study which examined physicians' use of communication technology for advising on burns injuries. ${ }^{31}$ The findings of our study suggest that it is also relevant to physicians' communication of poor prognosis in Ghana, and therefore transferable to other settings. In both studies, the pastoral element of this position was prominent, reflecting growing appreciation of the benefits of colleague-led learning and support, and a move towards health systems that increasingly acknowledge the value of supporting health workers themselves. ${ }^{58}$ In addition, the diversity of positions adopted during communication of poor prognosis reflects the complexity and associated cognitive burden such communication places on physicians. This has practical implications for improvement of physicians' communication training, emphasising contextual circumstances, increased involvement of allied professionals such as clinical psychologists and increased psychological support for physicians. These considerations are very topical in light of the current burnout epidemic among physicians. ${ }^{59}$ In addition, the diversity of positions identified in this study support the idea that clinical communication is underscored by creativity and originality, ${ }^{60}$ and contribute to the argument that clinical communication training may 
not be best suited to a reductionist paradigm which reduces skilled communication to technical 'communication skills'. ${ }^{24} 60$

\section{Development of international policy models}

Using this example of clinical practice to critique the five roles of physicians identified in the original WHO policy model of the '5-star doctor', we find evidence to suggest their relevance to communication of poor prognosis. ${ }^{25}$ The names of positions and roles are not identical, reflecting the very real semantic problem in attempting to summarise more abstract concepts, but the attributes are similar. As a caveat, the finding that physicians occasionally offered spiritual guidance to patients who requested it should not be taken to mean that religious knowledge should be part of physicians' competencies. Rather, the competency relates to the doctor's ability to recognise and practise the ethical principle of respecting patient autonomy; in this context, respecting the patient's right to choose to seek spiritual guidance as an adjunct to orthodox medicine.

However, there are also implications for development of policy models. First, the positions of mentor and protector do not feature in the models. ${ }^{25}{ }^{26}$ Both these positions place more emphasis on inherent qualities rather than skills learnt in training. Their identification suggests that physicians play roles with a clear link to their clinical training for example, clinical expert, but also roles which are far more difficult to train for. The acknowledgement that physicians cannot be prepared for every aspect of their clinical practice is important. In addition, the prominence of ethical complexities identified in this study suggests that the ethical aspect of physicians' work should be prioritised in consideration of their roles, in line with the recent recommendation of a working group from Denmark. ${ }^{26}$ There is also ongoing discussion as to whether physicians' roles are hierarchical, and if so whether being a clinical expert is most important. ${ }^{26}$ In this study, physicians considered themselves clinical experts as their default position, suggesting that they may view it as most important. However, they also saw clinical expertise as meaningless without other key skills, such as effective communication. Therefore, these findings support the argument that physicians' roles are not hierarchical, discrete entities but rather fluid and strongly interlinked. Thus, the concept of positions, which are more fluid than roles, might be relevant to future models; physicians shift positions even during shorter conversations. Future policy models should also consider a more explicit inclusion of relevance to local context, supporting calls for a radical overhaul of global medical education to create physicians who are socially accountable to the communities they serve. ${ }^{61}$

\section{Study limitations}

This study took place in one department within a tertiary level teaching hospital. Transferability is therefore limited to tertiary level hospitals under similar circumstances. ${ }^{62}$ Observation of communication might have improved quality but was not deemed possible due to language barriers and a concern that an observer may not be appropriate for potentially sensitive communication. A social desirability bias may have been introduced, since interviews were conducted by a fellow physician (AC) and facilitated by a physician who works with participants on a daily basis $(\mathrm{YN})$. To limit this effect, $\mathrm{YN}$ did not conduct interviews, and participants were reminded of their anonymity within the study and of the interviewer (AC's) capacity as a researcher. The potential sampling bias introduced by YN's involvement was in reality limited as few physicians were available for participation after excluding those absent, and applying the principle of sampling for maximum variation.

\section{CONCLUSION}

Positions adopted by physicians during communication of poor prognosis were diverse, and were shaped by considerations related to ethical principles, pluralistic health beliefs and wider health systems factors. Context was key to communication, with local challenges presented in the form of communication across languages, pluralistic health beliefs and ethical complexities relating to the role of family. This underlines the challenges of universality within clinical communication and the importance of understanding circumstances in which poor prognosis is communicated. Physicians' communication training should be developed to emphasise contextual circumstances of communication and provide greater support for this area of clinical practice, and international policy models which examine the roles of physicians should include a greater focus on context and social accountability.

Contributors AC, YAN, AP and HM-A made significant contributions to the study's conception and design. AC, YAN and HM-A participated in and/or were consulted during data collection in Cape Coast. The interview guide was designed by AC, YAN and HM-A. Data analysis was conducted primarily by AC, YAN and HM-A. Figures were designed by AC. All authors have revised the manuscript and cleared it for publication. All authors take responsibility for the content and ensure accuracy for the manuscript in full.

Funding The study received funding from the Swedish Research Council (Vetenskapsrådet).

Competing interests None declared.

Patient and public involvement Patients and/or the public were not involved in the design, or conduct, or reporting or dissemination plans of this research.

Patient consent for publication Not required.

Ethics approval Ethical approval for the study was granted by CCTH Ethical Review Board (Ref: CCTHERC/EC/2019/01).

Provenance and peer review Not commissioned; externally peer reviewed.

Data availability statement Data are available upon reasonable request.

Open access This is an open access article distributed in accordance with the Creative Commons Attribution Non Commercial (CC BY-NC 4.0) license, which permits others to distribute, remix, adapt, build upon this work non-commercially, and license their derivative works on different terms, provided the original work is properly cited, appropriate credit is given, any changes made indicated, and the use is non-commercial. See: http://creativecommons.org/licenses/by-nc/4.0/. 
ORCID iD

Alexandra Caulfield http://orcid.org/0000-0002-2483-4427

\section{REFERENCES}

1 Ezer T, Lohman D, de Luca GB. Palliative care and human rights: a decade of evolution in standards. J Pain Symptom Manage 2018;55:S163-9.

2 World Health Orgnization. Sustainable Development Goals for 2030. [Internet. Geneva: World Health Organizaion, 2019. https://www. who.int/sdg/targets/en/. (cited 11th December 2019).

3 World Health Organization. Definition of Palliative Care. [Internet. Geneva: World Health Organization, 2018. https://www.who.int/ cancer/palliative/definition/en/. (cited 11th December 2019).

4 World Health Organization. Strengthening of palliative care as a component of integrated treatment throughout the life course. J Pain Palliat Care Pharmacother 2014;28:130-4.

5 Palliative Care Alliance. Global Atlas of Palliative Care at the End of Life. [Internet. Geneva: World Health Organization, 2014. https:// www.who.int/nmh/Global Atlas of Palliative Care.pdf

6 Knaul FM, Farmer PE, Krakauer EL, et al. Alleviating the access abyss in palliative care and pain relief-an imperative of universal health coverage: the Lancet Commission report. Lancet 2018;391:1391-454.

7 Tulsky JA, Beach MC, Butow PN, et al. A research agenda for communication between health care professionals and patients living with serious illness. JAMA Intern Med 2017;177:1361-6.

8 Heyland DK, Allan DE, Rocker G, et al. Discussing prognosis with patients and their families near the end of life: impact on satisfaction with end-of-life care. Open Med 2009;3:e101-10.

9 Wright AA, Zhang B, Ray A, et al. Associations between end-of-life discussions, patient mental health, medical care near death, and caregiver bereavement adjustment. JAMA 2008;300:1665-73.

10 Robinson TM, Alexander SC, Hays M, et al. Patient-oncologist communication in advanced cancer: predictors of patient perception of prognosis. Support Care Cancer 2008;16:1049-57.

11 Fried TR, Bradley EH, Towle VR, et al. Understanding the treatment preferences of seriously ill patients. N Engl J Med 2002;346:1061-6.

12 Bail K. Patient and professional dissatisfaction: a literature review of prognosis communication related to hospital settings. Contemp Nurse 2008;29:135-46.

13 Dias L, Chabner BA, Lynch TJ, et al. Breaking bad news: a patient's perspective. Oncologist 2003;8:587-96.

14 Dare F. The High Cost of Nurses' Communication Challenges. [Internet] Cisco Internet Business Solutions Group (IBSG), 2009. Available: https://www.cisco.com/c/dam/en_us/about/ac79/docs/ Nurses Survey_Report_0923FINAL.pdf [Accessed 11 Dec 2019].

15 Ganca LL, Gwyther L, Harding R, et al. What are the communication skills and needs of doctors when communicating a poor prognosis to patients and their families? A qualitative study from South Africa. S Afr Med J 2016;106:940-4.

16 Lewis EG, Oates LL, Rogathi J, et al. We never speak about death Healthcare professionals' views on palliative care for inpatients in Tanzania: A qualitative study 2018;16:566-79.

17 Schallmo MK, Dudley-Brown S, Davidson PM. Healthcare providers perceived communication barriers to offering palliative care to patients with heart failure: an integrative review. J Cardiovasc Nurs 2019;34:E9-18.

18 Institute of Medicine (U.S.). Committee on approaching death. dying in America: improving quality and honoring individual preferences near the end of life. Washington, District of Columbia: The National Academies Press, 2015.

19 Hagerty RG, Butow PN, Ellis PA, et al. Cancer patient preferences for communication of prognosis in the metastatic setting. J Clin Oncol 2004;22:1721-30.

20 Caldwell PH, Arthur HM, Demers C. Preferences of patients with heart failure for prognosis communication. Can $J$ Cardiol 2007;23:791-6.

21 Fumis RRL, De Camargo B, Del Giglio A. Physician, patient and family attitudes regarding information on prognosis: a Brazilian survey. Ann Oncol 2012;23:205-11.

22 Gordon NA, O'Riordan DL, Dracup KA, et al. Let us talk about it: heart failure patients' preferences toward discussions about prognosis, advance care planning, and spiritual support. J Palliat Med 2017;20:79-83.

23 Dennison L, Brown M, Kirby S, et al. Do people with multiple sclerosis want to know their prognosis? A UK nationwide study. PLoS One 2018;13:e0193407.
24 Salmon P, Young B. A new paradigm for clinical communication: critical review of literature in cancer care. Med Educ 2017;51:258-68.

25 Boelen C. The five star doctor: An asset to health care reform? [Internet. Geneva: World Health Organization, 1993. http://158.232.12.119/hrh/en/HRDJ_1_1_02.pdf. (cited 11th December 2019)

26 Danish Health and Medicines Authority. The Seven Roles of Physicians. [Internet. Copenhagen: Danish Health and Medicines Authority, 2014. https://www.sst.dk/en/news/2013/ /media/39D3 E216BCBF4A9096B286EE44F03691.ashx. (cited 11th December 2019).

27 Morales IDR, Fernández JA, Durán F. Cuban medical education: aiming for the six-star doctor. MEDICC Rev 2008;10:5-9.

28 Universitas Indonesia. Medical Doctor. [Internet] Universitas Indonesia, 2019. Available: https://www.ui.ac.id/en/professional/ medical-doctor.html [Accessed 11 Dec 2019].

29 Jha N, Premarajan KC, Nagesh S, et al. Fiv-star doctors for the 21st century: a BPKIHS endeavour for Nepal. Journal of Health Management 2005;7:237-47.

30 Harré R, Moghaddam FM, Cairnie TP, et al. Recent advances in positioning theory. Theory Psychol 2009;19:5-31.

31 Blom L, Laflamme L, Mölsted Alvesson H. Expectations of medical specialists about image-based teleconsultation - A qualitative study on acute burns in South Africa. PLoS One 2018;13:e0194278.

32 Martis L, Westhues A. A synthesis of the literature on breaking bad news or truth telling: potential for research in India. Indian J Palliat Care 2013;19:2-11.

33 Medical and Dental Council Ghana. Revised guidelines for Housemanship in Ghana. Accra: Medical and Dental Council Ghana, 2015. http://www.mdcghana.org/docs/GUIDELINES-ONHOUSEMANSHIP-TRAINING-2015.pdf

34 Edwin AK, Johnson McGee S, Opare-Lokko EA, et al. A structured approach to end-of-life decision making improves quality of care for patients with terminal illness in a teaching hospital in Ghana. Am J Hosp Palliat Care 2016;33:144-9.

35 Institute for Health Metrics and Evaluation (IHME). GBD Compare [Internet. Seattle, WA: University of Washington, 2015. https:// vizhub.healthdata.org/gbd-compare/. (cited 11th December 2019).

36 The World Bank. Life expectancy at birth, total (years) - Ghana [Internet]. The World Bank, 2017. Available: https://data.worldbank. org/country/ghana [Accessed cited 11th December 2019].

37 Kpessa-Whyte M. Aging and demographic transition in Ghana: state of the elderly and emerging issues. Gerontologist 2018;58:403-8.

38 Central Intelligence Agency. The World Factbook [Internet]. Central Intelligence Agency, 2019. Available: https://www.cia.gov/library/ publications/the-world-factbook/geos/gh.html [Accessed $11 \mathrm{DeC}$ 2019].

39 Nsiah-Boateng E, Aikins M. Trends and characteristics of enrolment in the National health insurance scheme in Ghana: a quantitative analysis of longitudinal data. Glob Health Res Policy 2018;3:32.

40 The World Bank. Literacy rate, adult total (\% of people aged 15 and above) - Ghana [Internet. The World Bank, 2018. https://data. worldbank.org/indicator/SE.ADT.LITR.ZS?locations $=\mathrm{GH}$

41 Ghana Statistical Service. 2010 Population and housing census summary report of final results [Internet. Ghana Statistical Service, 2012. https://www.statsghana.gov.gh/gssmain/storage/img/ marqueeupdater/Census2010_Summary_report_of_final_results.pdf

42 World Health Organization. Legal Status of Traditional Medicine and Complementary/Alternative Medicine: A Worldwide Review [Internet. Geneva: World Health Organization, 2001. https://apps.who.int/ medicinedocs/pdf/h2943e/h2943e.pdf. (cited 11th December 2019).

43 Kpobi L, Swartz L. Implications of healing power and positioning for collaboration between formal mental health services and traditional/ alternative medicine: the case of Ghana. Glob Health Action 2018;11:1445333.

44 Kpobi L, Swartz L. Indigenous and faith healing in Ghana: a brief examination of the formalising process and collaborative efforts with the biomedical health system. Afr J Prim Health Care Fam Med 2019;11:e1-5.

45 Rhee JY, Garralda E, Namisango E, et al. Factors affecting palliative care development in Africa: In-Country experts' perceptions in seven countries. J Pain Symptom Manage 2018;55:1313-20.

46 Rhee JY, Garralda E, Namisango E, et al. An Analysis of Palliative Care Development in Africa: A Ranking Based on Region-Specific Macroindicators. J Pain Symptom Manage 2018;56:230-8.

47 Economist Intelligence Unit. The 2015 Quality of Death Index: ranking palliative care across the world. [Internet]. The Economist Intelligence Unit, 2015. Available: https://eiuperspectives.economist. com/sites/default/files/2015\%20EIU\%20Quality\%20of\%20Death\% 20Index\%200ct\%2029\%20FINAL.pdf [Accessed 11 DeC 2019]. 
48 Hoeyer Ket al. What is theory, and how does theory relate to method? In: Vallgårda SKL, Bjerg $\mathrm{O}$, Christensen $\mathrm{U}$, et al, eds. Research methods in public health. Copenhagen: Gyldendal Akademisk, 2008.

49 Tong A, Sainsbury P, Craig J. Consolidated criteria for reporting qualitative research (COREQ): a 32-item checklist for interviews and focus groups. Int J Qual Health Care 2007;19:349-57.

50 Birt L, Scott S, Cavers D, et al. Member checking: a tool to enhance Trustworthiness or merely a NOD to validation? Qual Health Res 2016;26:1802-11.

51 Malterud K, Siersma VD, Guassora AD. Sample size in qualitative interview studies: guided by information power. Qual Health Res 2016;26:1753-60.

52 Braun V, Clarke V. Using thematic analysis in psychology. Qual Res Psychol 2006;3:77-101.

53 Clarke V, Braun V. Thematic analysis. J Posit Psychol 2017;12:297-8.

54 Barimah KB, Akotia CS. The promotion of traditional medicine as enactment of community psychology in Ghana. J Community Psychol 2015;43:99-106.
55 Gilbar R, Miola J. One size fits all? on patient autonomy, medical decision-making, and the impact of culture. Med Law Rev 2015;23:375-99.

56 Nwankwo KC, Ezeome E. The perceptions of physicians in Southeast Nigeria on truth-telling for cancer diagnosis and prognosis. J Palliat Med 2011;14:700-3.

57 Rajashekharaiah $\mathrm{H}$. Health worker safety in the context of largescale outbreak response. Humanitarian Health Digest 2019;3.

58 O'Dowd E, O'Connor P, Lydon S, et al. Stress, coping, and psychological resilience among physicians. BMC Health Serv Res 2018;18:730.

59 Atallah F, McCalla S, Karakash S, et al. Please put on your own oxygen mask before assisting others: a call to arms to battle burnout. Am J Obstet Gynecol 2016;215:731.e1-731.e6.

60 Salmon P, Young B. Creativity in clinical communication: from communication skills to skilled communication. Med Educ 2011;45:217-26.

61 Ebrahim S, Squires N, di Fabio JL, et al. Radical changes in medical education needed globally. Lancet Glob Health 2015;3:e128-9.

62 Malterud K. Qualitative research: Standards, challenges, and guidelines. The Lancet 2001;358:483-8. 